\title{
HUBUNGAN PENGETAHUAN IBU DENGAN TINGKAT KECEMASAN DALAM MENGHADAPI MASA KLIMAKTERIUM DI RSUD TASIKMALAYA
}

\author{
Arifah Septiane Mukti \\ Program Studi DIII Kebidanan, Fakultas Ilmu Kesehatan, Universitas Galuh \\ Email Corresponding : arifah_mukti@yahoo.com \\ (Diterima 25-10-2019; disetujui 18-11-2019; dipublish 27-11-2019)
}

\begin{abstract}
Abstrak
Klimakterium merupakan masa peralihan antara masa reproduksi dan masa senium. Biasanya masa ini disebut juga dengan pramenopause, antara usia 40 tahun, ditandai dengan siklus haid yang tidak teratur, dengan perdarahan haid yang memanjang dan relatif banyak.Tujuan penelitian ini untuk mengetahui hubungan pengetahuan ibu dengan tingkat kecemasan dalam menghadapi masa klimakterium di RSUD Tasikmalaya. Jenis penelitian yang digunakan adalah korelasional atau asosiasi. Populasi dalam penelitian ini adalah ibu yang berusia 30-60 tahun dan berkunjung ke Poliklinik Kandungan RSUD Tasikmalaya yang berdasarkan data tahun 2017 sebanyak 3015 orang. Pemilihan sampel dalam penelitian ini adalah menggunakan tehnik accidental sampling Banyaknyaknya sampel dalam penelitian ini adalah sebanyak 97 orang .Hasil penelitian Uji statistik didapatkan bahwa Pengetahuan Ibu dengan Kecemasan Pada Masa Klimakterium ( $\mathrm{P}=$ 0,000). Mempunyai hubungan Pengetahuan Ibu dengan Kecemasan Pada Masa Klimakterium RSUD Tasikmalaya. Berdasarkan hasil penelitian diharapkan tenaga kesahatan lebih menerapkan komunikasi terapeutik kepada pasien agar mengurangi tingkat kecemasan pada pasien.

Kata Kunci : Pengetahuan, kecemasan, masa klimakterium.
\end{abstract}

\section{Abstract}

Climacterium is a transitional period between the reproductive period and the senium period. Usually this period is also called premenopause, between the age of 40 years, marked by irregular menstrual cycles, menstrual bleeding that extends and is relatively numerous. The research used is correlational or association. The population in this study were mothers aged 30-60 years who visited the Gynecology Clinic of Tasikmalaya Regional Hospital based on 2017 data of 3015 people. The sample selection in this study was to use accidental sampling technique. The number of samples in this study was 97 people. The results of the statistical test found that the mother's knowledge with anxiety during climacteric period $(P=0,000)$. Having a relationship between Mother's Knowledge and Anxiety During the Climacterium of Tasikmalaya Regional Hospital. Based on the results of the study, it is expected that health professionals will apply therapeutic communication to patients in order to reduce the level of anxiety in patients.

Keywords: Knowledge, anxiety, climacteric period.

\section{PENDAHULUAN}

Klimakterium merupakan masa peralihan antara masa reproduksi dan masa senium. Biasanya masa ini disebut juga dengan pramenopause, antara usia 40 tahun, ditandai dengan siklus haid yang tidak teratur, dengan perdarahan haid yang memanjang dan relatif banyak (Nugroho.T,2010:75). Sebagian besar wanita mulai mengalami gejala menopause pada 
usia 40-an dan puncaknya tercapai pada usia 50 tahun (Manuaba 2010:80).

Kemajuan di dalam bidang teknologi kesehatan telah meningkatkan usia harapan hidup bagi manusia, sehingga setiap tahun jumlah penduduk lansia terus bertambat. Bazias (2003) menyebutkan pada tahun 1997 penduduk Indonesia telah mencapai 201,4 juta dengan 100,9 juta orang perempuan dan diantaranya perempuan berusia di atas 50 thun mencapai 14,3 juta orang dan pada tahun 2000 jumlah perempuan mencapai 203,46 juta orang yang terdiri dari 101,81 juta perempuan dengan jumlah perempuan yang berusia di atas 50 tahun yang diperkirakan telahmemasuki usia menopause sebanyak 15,5 juta orang dan ada tahun 2020 diperkirakan jumlah perempuan yang hidup dalam masa klimakterium di Indonesia adalah 30,3 juta orang.

Data yang diperoleh dari wilayah RSUD Tasikmalaya Januari-Mei 2018 jumlah wanita masa klimakterium yang berkunjung ke RSUD Tasikmalaya sebanyak 114 orang.

Berdasarkan hasil studi pendahuluan yang penulis lakukan dengan mewawancarai 10 ibu pada masa klimakterium yang berkunjung ke RSUD Tasikmalaya menunjukkan bahwa hanya 2 orang yang mempunyai pengetahuan baik tentang klimakterium dengan tingkat kecemasan yang ringan. Sedangkan 8 orang lagi tidak mengetahui usia klimakterium dengan 5 diantaranya memiliki tingkat kecemasan yang berat karena mereka merasa belum siap dengan tanda dan gejala yang dihadapi pada masa kimakterium. Berdasarkan uraian diatas penulis tertarik untuk melakukan penelitian tentang Hubungan Pengetahuan Ibu dengan Kecemasan Pada Masa Klimakterium di RSUD Tasikmalaya.

Salah satu faktor seseorang cemas dalam menghadapi masa klimakterium adalah pengetahuan.

Secara garis besar periode daur kehidupan wanita melampaui beberapa tahap diantaranya pra konsepsi, konsepsi, pra kelahiran, pra pubertas, pubertas, reproduksi, klimakterium dan senium/lansia. Sepanjang daur kehidupan seorang wanita akan mengalami satu masa yang sifatnya fisiologis, sebagai fase dimana proses penuaan wanita ditandai dengan perpindahan dari masa reproduksi ke masa non produksi yang dinamakan periode klimakterium (Wiknjosastro, 2002).

Pada wanita klimakterium akan mengalami penuaan indung telur, sehingga tidak sanggup memenuhi hormon estrogen. Sistem hormonal seluruh tubuh mengalami kemunduran yang menyebabkan berbagai perubahan pada fisik dan psikis (Manuaba, 2002). Keluhan yang pertama kali dirasakan adalah keluhan vasomotor (yang berhubungan dengan pembuluh darah) seperti hot fishes (semburan panas tiba-tiba di wajah, leher dan dada), night sweats (keringat berlebihan di malam hari) dan atrofi urogenital (penipisan mukosa vagina) yang menimbulkan akibat lanjut berupa kekeringan liang vagina sehingga saat berhubungan suami istri terasa sakit dan terjadi penurunan libido. Keluhan lain yang dianggap sebagai gejala psikis dan sosial budaya, misalnya depresi sakit kepala (Mulyani, 2013).

Banyak dari anggota masyarakat yang menanggapi klimakterium sebagai masalah yang rumit karena kurang pengetahuan tentang masalah yang mereka hadapi, karena banyak mitos yang menyesatkan tentang apa menopause, sehingga dapat menimbulkan konflik yang datang dari diri mereka sendiri yang justru dapat menimbulkan masalah baru yang seharusnya tidak muncul seperti konflik di dalam keluarga. Tetapi biasanya kecemasan yang mereka hadapi adalah karena takut kehilangan peran sebagai wanita, takut kesepian dan tidak ada teman yang mau diajak bicara atau diminta nasehat (Mansjoer, 2010).

Tanda dan gejala pada masa klimakterium adalah gangguan Fisik seperti kelainan menstruasi (siklus haid yang memanjang, haid tidak teratur, darah haid yang banyak), Keluhan kontitusional Palpitasi, sakit kepala (migrain), kelelahan, nyeri otot sendi, nyeri punggung, peningkatan berat badan.

\section{METODE PENELITIAN}

Penelitian ini termasuk jenis penelitian korelasional atau asosiasi yaitu penelitian yang mengkaji hubungan antara variabel 
sehingga peneliti dapat menjelaskan suatu hubungan, memperkirakan, dan mengujinya berdasarkan teori yang ada. Penelitian korelasional bertujuan untuk mendeteksi sejauh mana variasi-variasi pada suatu faktor berhubungan dengan variasi-variasi pada satu atau lebih faktor lain tanpa melakukan intervensi tertentu terhadap variasi variabel-variabel yang bersangkutan (Nursalam, 2010).

Populasi pada penelitian ini adalah ibu yang berusia 30-60 tahun dan berkunjung ke Poliklinik Kandungan RSUD Tasikmalaya yang berdasarkan data tahun 2017 sebanyak 3015 orang.

$$
\begin{aligned}
& n=\frac{N}{1+N\left(d^{2}\right)} \\
& n=\frac{3015}{1+3015\left(0,1^{2}\right)} \\
& n=\frac{3015}{31,15} \\
& n=96,7 \\
& \mathrm{n}=97 \text { orang } \\
& \text { Keterangan : } \\
& \mathrm{n} \quad=\text { Jumlah sampel } \\
& \mathrm{N} \quad \text { Jumlah populasi } \\
& \mathrm{d} \quad \text { = Tingkat kepercayaan }(0,1)
\end{aligned}
$$

Dari hasil perhitungan diatasa maka sampel yang dijadikan sebagai subyek penelitian adalah 97 responden.

Tekhnik penentuan sampel dalam penelitian ini menggunakan teknik accidental sampling yaitu pengambilan sampel yang dilakukan dengan mengambil sampel yang kebetulan ada dan tersedia saat penelitian dilakukan yaitu ibu usia 30-60 tahun yang melakukan kunjungan ke Poliklinik Kandungan RSUD Tasikmalaya.

Adapun kriteria inklusi dalam penentuan sampel pada penelitian ini adalah :

a. Ibu yang berusia 30-60 tahun pada saat penelitian berlangsung,

b. Ibu bersedia menjadi responden

c. Ibu berada ditempat pada saat penelitian berlangsung

d. Ibu dapat berkomunikasi dengan baik

Sedangkan kriteria eksklusi dalam penentuan sampel pada penelitian ini adalah:

a. Ibu berusia dibawah 30 tahun b. Ibu yang tidak bersedia menjadi responden

c. Ibu sedang sakit

Jenis data pada penelitian ini adalah data Primer dan Sekunder. Data primer adalah data yang didapatkan secara langsung dari responden melalui wawancara terstruktur dengan menggunakan kuesioner terstruktur (Arikunto, 2006).

Data Primer dalam penelitian ini adalah data yang diperoleh dengan membagikan kuesioner yang disususn sesuai dengan indikator dari variabel penelitian dan jawabannya sudah disediakan sehingga responden tinggal memilih.). Untuk kuesioner pengetahuan responden hanya melingkari setiap jawaban a, b, atau c yang dianggap benar. Sedangkan untuk kuesioner tentang kecemasan responden diminta membubuhkan tanda checklist $(\sqrt{ })$ pada skor yang sudah disediakan.

Data sekunder adalah bentuk sumber informasi yang berhubungan dengan dokumen, baik dokumen-dokumen resmi maupun tidak resmi (Nursalam, 2010). Dalam penelitian ini data sekunder diperoleh melalui studi kepustakaan dengan melakukan pencarian data dalam literatur dan dokumen di RSUD Tasikmalaya.

\section{HASIL PENELITIAN}

Hasil penelitian ini akan di tuangkan dalambentuk tabel sebagai berikut :

1. Analisis Univariat

Analisis univariat dilakukan terhadap tiap variabel dari hasil penelitian. Pada umumnya hasil analisis ini hanya menghasilkan distribusi dan prosentase dari setiap variabel (Badriah, 2006).

Tabel 1

Distribusi Frekuensi Berdasarkan Usia di Poliklinik Kandungan RSUD Tasikmalaya

\begin{tabular}{|c|l|c|c|}
\hline No & \multicolumn{1}{|c|}{ Umur } & Jumlah & \% \\
\hline 1 & $\begin{array}{l}40-50 \\
\text { tahun }\end{array}$ & 7 & 7,2 \\
\hline 2 & $\begin{array}{l}50-60 \\
\text { tahun }\end{array}$ & 82 & 84,6 \\
\hline 3 & $>60$ Tahun & 8 & 8,2 \\
\hline \multicolumn{2}{|c|}{ Total } & 97 & 100 \\
\hline
\end{tabular}

Sumber: Data Olahan Penelitian 
Berdasarkan tabel 1 diketahui bahwa usia responden dalam penelitian ini lebih banyak yang berusia antara 50-60 tahun yaitu 82 orang $(84,6 \%)$, usia $>60$ tahun sebanyak 8 orang $(8,2 \%)$, dan usia 40-50 tahun sebanyak 7 orang $(7,2 \%)$.

Tabel 2

Distribusi Frekuensi Berdasarkan Pendidikan di Poliklinik Kandungan RSUD Tasikmalaya

\begin{tabular}{|c|l|c|c|}
\hline No & Pendidikan & Jumlah & \% \\
\hline 1 & SD & 69 & 71,1 \\
\hline 2 & SMP & 17 & 17,6 \\
\hline 3 & SMA & 1 & 1.0 \\
\hline 4 & $\begin{array}{l}\text { Perguruan } \\
\text { Tinggi }\end{array}$ & 10 & 10,3 \\
\hline \multicolumn{2}{|c|}{ Total } & 97 & 100 \\
\hline
\end{tabular}

Berdasarkan tabel 4.2 diketahui bahwa pendidikan responden dalam penelitian ini lebih banyak lulusan SD yaitu 69 orang $(71,1 \%)$, pendidikan SMP sebanyak 17 orang $(17,6 \%)$, perguruan tinggi sebanyak 10 orang $(10,3 \%)$, dan SMA sebanyak 1 orang $(1,0 \%)$.

\section{Analisis Univariat \\ Pengetahuan}

Tabel 3

Distribusi Frekuensi Berdasarkan

Pengetahuan Pada Masa Klimakterium di Poliklinik Kandungan

\begin{tabular}{|c|c|c|c|}
\hline No. & Pengetahuan & $\begin{array}{l}\text { Frekuensi } \\
\text { (f) }\end{array}$ & $\begin{array}{c}\text { Prosentase } \\
(\%)\end{array}$ \\
\hline 1. & Kurang & 55 & 56.7 \\
\hline 2. & Cukup & 14 & 14.4 \\
\hline 3. & Baik & 28 & 28.9 \\
\hline & Jumlah & 97 & 100 \\
\hline
\end{tabular}

\section{Sumber:Data Olahan}

Tabel di atas menunjukkan bahwa dari 97 responden ada $55(56.7 \%)$ responden dengan pengetahuan kurang, 28 (28.9\%) responden dengan pengetahuan baik, dan 14 (14.4\%) responden dengan pengetahuan cukup.

\section{Kecemasan}

Tabel 4

Distribusi Frekuensi Berdasarkan Kecemasan pada Masa Klimakterium di Poliklinik Kandungan

\begin{tabular}{c|l|c|c|}
\hline No. & Kemampuan & Frekuensi (f) & Prosentase (\%) \\
\hline & & & \\
1. & Tidak Cemas & 0 & 00.0 \\
2. & Cemas Ringan & 9 & 9.3 \\
3. & Cemas Sedang & 11 & 11.3 \\
4. & Cemas Berat & 77 & 79.4 \\
\hline \multicolumn{2}{|c|}{ Jumlah } & $\mathbf{9 7}$ & $\mathbf{1 0 0}$
\end{tabular}

\section{Sumber: Data Olahan}

Tabel di atas menunjukkan bahwa dari 97 responden ada $77(79.4 \%)$ responden dengan kecemasan berat, 11 responden $(11,3 \%)$ cemas sedang dan .9 responden $(9,3 \%)$ responden dengan kecemasan ringan.

\section{Analisis Bivariat}

Tabel 5

Distribusi Frekuensi Berdasarkan

Hubungan Pengetahuan dengan

Kecemasan pada Masa Klimakterium di

Poliklinik Kandungan RSUD Tasikmalaya

\begin{tabular}{|c|c|c|c|c|c|c|c|c|c|}
\hline \multirow{3}{*}{ Variabel } & \multicolumn{6}{|c|}{ Kecemasan } & \multirow{2}{*}{\multicolumn{2}{|c|}{$\sum$}} & \multirow{3}{*}{$\begin{array}{c}\mathrm{P} \\
\text { Value }\end{array}$} \\
\hline & \multicolumn{2}{|c|}{ Ringan } & \multicolumn{2}{|c|}{ Sedang } & \multicolumn{2}{|c|}{ Berat } & & & \\
\hline & $\mathrm{F}$ & $\%$ & $\mathrm{f}$ & $\%$ & $f$ & $\%$ & F & $\%$ & \\
\hline Pengetahuan: & & & & & & & & & \\
\hline Baik & 9 & 32,1 & & 35,7 & 9 & 32,1 & 28 & 100 & 0.000 \\
\hline - Cukup & 0 & 0 & 0 & 0 & 14 & 100 & 14 & 100 & \\
\hline - Kurang & 0 & 0 & 1 & 1,8 & 54 & 98,2 & 55 & 100 & \\
\hline Jumlah & 9 & 9,3 & 11 & 11,3 & 77 & 79,4 & $\frac{1}{1}$ & 100 & \\
\hline
\end{tabular}

\section{Sumber : Data Olahan}

Tabel 4.5 menunjukkan bahwa dari $55 \mathrm{Ibu}$ masa klimakterium yang pengetahuannya kurang lebih banyak yang cemas berat yaitu 54 orang $(98,2 \%)$, cemas sedang 1 orang $(1,8 \%)$. Ibu masa klimakterium yang memiliki pengetahuan cukup yaitu 14 orang semuanya $(100 \%)$ cemas berat. Ibu masa klimakterium yang memiliki pengetahuan baik yaitu 28 orang lebih banyak yang cemas sedang yaitu 10 orang $(35,7 \%)$ daripada yang cemas berat yaitu 9 orang $(32,1 \%)$. Hasil uji Chi Square didapatkan nilai $\mathrm{p}=0.000<\alpha$ 0,05 hal ini mengandung arti bahwa ada hubungan antara pengetahuan dengan kecemasan pada masa Klimakterium.

\section{PEMBAHASAN}

\section{Pengetahuan}

Hasil penelitian tentang variabel pengetahuan didapatkan ada $56.7 \%$ responden dengan pengetahuan kurang, $14.4 \%$ responden 
dengan pengetahuan cukup dan ada $28.9 \%$ responden dengan pengetahuan baik. Data ini memperlihatkan bahwa masih tingginya responden yang mempunyai pengetahuan kurang tentang klimekterium, hal ini akan sangat mempengaruhi terhadap bagaimana cara pandang dan tanggapan responden mengenai klimekterium tersebut.

Kurangnya pengetahuan responden tentang klimakterium salah satunya disebabkan oleh pendidikan responden yang sebagian besar lulusan SD yaitu yaitu 69 orang $(71,1 \%)$. Hal ini sesuai dengan yang dikemukakan Notoadmodjo (2012) bahwa pendidikan adalah upaya untuk memberikan pengetahuan sehingga terjadi perubahan perilaku positif yang meningkat. Semakin tinggi pendidikan seseorang makin mudah orang tersebut untuk menerima informasi. Dengan pendidikan tinggi maka seseorang akan cenderung untuk mendapatkan informasi baik dari orang lain maupun dari media masa, sebaliknya tingkat pendidikan yang kurang akan menghambat perkembangan dan sikap seseorang terhadap nilai-nilai yang baru diperkenalkan.

\section{Kecemasan}

Hasil penelitian untuk variabel kecemasan dari 97 responden ada 77 (79.4 $\%)$ responden dengan kecemasan berat, 11 responden $(11,3 \%)$ cemas sedang dan .9 responden $(9,3 \%)$ responden dengan kecemasan ringan. Artinya semua ibu-ibu yang menjadi responden pada penelitian ini mengalami kecemasan pada masa klimakterium dan ternyata lebih dari tiga perempatnya ibu-ibu tersebut mengalami kecemasan berat. Hal ini dikarenakan sebagian besar responden berpendidikan SD sehingga kurang mengetahui tentang klimakterium. Hal ini sebagaimana dikemukakan oleh Astuti (2010) bahwa Perilaku wanita klimakterium dipengaruhi oleh faktor pendidikan karena dengan pendidikan semakin tinggi maka seseorang dpat menggali informasi lebih dalam berbed dengan seseorang yang berpengetahuan rendah. Wanita yang banyak mengalami kekhawatiran berasal dari orang-orang yang berpendidikan rendah. Kecemasan pada masa klimakterium sangat mempengaruhi emosional orang yang mengalaminya seperti yang dikatakan oleh Stuart \& Sundeen (2003) Kecemasan adalah respon emosional terhadap penilaian yang berkaitan dengan perasaan tidak pasti dan tidak berdaya. Keadaan emosi ini tidak memiliki objek yang spesifik. Kecemasan berbeda dengan rasa takut, yang merupakan penilaian intelektual terhadap sesuatu yang berbahaya. Pada saat itu ibu-ibu mengalami perasaan tidak pasti dan tidak berdaya akan suatu keadaan yang sebernarnya belum tentu terjadi, seperti kecemasan akan terganggunya peran sebagai seorang istri bagi suaminya serta kecemasankecemasan linnya yang sebenarnya hanya perasaan subjektif saja.

\section{Hubungan Pengetahuan dengan Kecemasan}

Hasil uji Chi Square didapatkan nilai $\mathrm{p}=$ $0.000<\alpha 0,05$ hal ini mengandung arti bahwa ada hubungan antara pengetahuan dengan kecemasan pada masa Klimakterium di Poliklinik Kandungan RSUD Tasikmalaya.

Adanya hubungan antara pengetahuan dengan kecemasan pada penelitian ini menunjukkan bahwa pengetahuan diperlukan untuk mengurangi kecemasan ibu masa klimakterium dalam menghadapi suatu masa berhentinya haid secara permanen. Sebab pengetahuan merupakan suatu bagian dari setiap orang yang dapat mengubah persepsi. Hal ini sesuai dengan yang dikemukakan oleh Notoatmodjo (2010) bahwa Pengetahuan atau kognitif merupakan domain yang sangat penting dalam membentuk tindakan seseorang (over behavior). Meningkatnya pengetahuan dapat menimbulkan perubahan persepsi, kebiasaan dan membentuk kepercayaan seseorang. Hal ini terlihat dari ibu masa klimakterium yang memiliki pengetahuan baik yaitu 28 orang lebih banyak yang cemas sedang yaitu 10 orang $(35,7 \%)$, dan dari 55 Ibu masa klimakterium yang pengetahuannya kurang lebih banyak yang cemas berat yaitu 54 orang $(98,2 \%)$.

Kecemasan yang dialami ibu klimakterium lebih disebabkan karena perasaan takut atau tidak tenang yang sumbernya tidak jelas dialami oleh ibu-ibu. 
Reaksi psiologis dapat berupa kecemasan yang ditandai oleh palpitasi, keringat dingin pada telapak tangan, tekanan darah meningkat, respirasi meningkat, peristaltik usus meningkat, sedangkan reaksi psikologis dapat berupa gugup, tegang, rasa tidak enak, dan lekas terkejut.

Perasaan takut tersebut dikarenakan ketidaktahuan ibu tentang suatu masa terjadinya penurunan fertilitas serta menstruasi yang ireguler bahkan kadangkadang berhenti. Hal ini terlihat dari sejumlah pertanyaan dalam kuesioner tidak dapat dijawab dengan benar oleh responden. Oleh karena itu untuk mengurangi kecemasan ibu masa klimakterium diharapkan petugas kesehatan memberikan konseling yang dapat meningkatkan pengetahuan ibu tentang klimakterium. Kartono (2002)

\section{SIMPULAN DAN SARAN}

Pengetahuan ibu tentang masa klimakterium di Poli Kandungan RSUD Tasikmalaya sebagian besar termasuk kategori kurang yaitu 55 orang $(56.7 \%)$. Kecemasan ibu tentang masa klimakterium di Poli Kandungan RSUD Tasikmalaya sebagian besar termasuk kategori cemasan berat yaitu 77 orang (79.4\%). Ada hubungan antara pengetahuan dengan kecemasan pada masa Klimakterium di Poli Kandungan Tasimlaya dengan $p$-value $=0.000<\alpha 0,05$. Diharapkan rumah sakit bekerja sama dengan puskesmas - puskesmas mengadakan penyuluhanpenyuluhan pada lansia tentang klimakterium sehingga ibu mendapatkan pengetahuan tentang klimakterium dan memberikan suport bahwa masa klimakterium merupakan hal yang biasa terjadi pada wanita sehingga tidak perlu dicemaskan.

\section{DAFTAR PUSTAKA}

1. Arikunto, Suharsimi. 2006. Prosedur Penelitian, Suatu Pendekatan Praktek, Rineka Cipta. Jakarta

2. Astuti. 2010. Gambaran Pengetahuan Ibu Usia 40-50 tahun Dalam Menghadapi Masa Menopause di Kecamatan Padang Hilir Tebing
Tinggi Tahun 2010. Journal Bunda Sejati

3. Badriah DL, 2006.Metodologi Penelitian Ilmu Ilmu Kesehatan. Multazam, Bandung.

4. Baziad, A. 2003. Menopause dan Andropause. Jakarta : Yayasan Bina Pustaka Sarwono Prawirohardjo.

5. Data RSUD Tasikmalaya Tahun 2018

6. Kartono, K. 2002. Psikologi Wanita Jilid 2: Mengenal Wanita Sebagai Ibu Dan Nenek. Bandung: Mandar Maju

7. Mansjoer.2010.Kapita Selekta Kedokteran. Edisi 4. Jakarta : Medika Aesculapius

8. Manuaba. 2010. Memahami Kesehatan Reproduksi Wanita. Jakarta : Arcan.

9. Mulyani, S (2013). Menopause Akhir Siklus Menstruasi Pada Wanita di Usia Pertengahan. Yogyakarta: Nuha Medika.

10. Notoatmodjo, S. 2010. Metodologi Penelitian Kesehatan, PT. Rineka Cipta, Jakarta.

11. Nursalam, 2010. Konsep Penerapan Metodelogi Penelitian Ilmu Keperawatan. Surabaya; Salemba Medika

12. Wiknjosastro,Hanifa.2002. Ilmu Kebidanan. Yayasan Bina PustakaSarwono Prawirohardjo.Jakarta. 